\title{
In-between spaces of policy and practice: Voices from Prince Edward Island early childhood educators
}

\author{
Gabriela Arias de Sanchez', Alaina L. Roach O’'Keefe², Bethany Robichaud ${ }^{3}$
}

\begin{abstract}
Over the course of the past decades, the discourse, pedagogy, scope, and delivery of early learning and child care (ELCC) has undergone myriad significant changes internationally, nationally, and at local levels. Prince Edward Island (PEI), the smallest Canadian Province, has not been exempt from these transformations. By situating early childhood educators (ECEs) at the centre of ecological multilevel environments (Bronfenbrenner, 2005), this qualitative study explored how a system-wide change implemented through the Prince Edward Island Preschool Excellence Initiative (PEIPEI) has impacted and is being impacted by ECEs over time. Purposive sampling was used to invite seven early childhood educators working on provincially regulated early years centres (EYCs) to participate in individual interviews. Findings indicated that ECEs have been striving to navigate and merge the space in-between policy and practices and that after ten years, they remain in this liminal space where they continue to navigate unravelling transitions as they search for their professional identity.
\end{abstract}

\section{Article History}

Received: 21 May 2021

Accepted: 03 July 2021

Keywords

Early childhood educators;

Policy; Transitions

\section{Introduction}

Over the course of the past decades, the discourse, pedagogy, scope, and delivery of early learning and child care (ELCC) has undergone myriad significant changes internationally, nationally, and at local levels including massive government financial investments, changes of ELCC government responsibility from health and social services to education portfolios, and an effort to connect childcare with education which has resulted in the creation of curriculum frameworks and an intent to standardize educators' training. Prince Edward Island (PEI) has not been exempt from these transformations. Located on Canada's east coast, the country's smallest province has emerged as a leader of the shifts that have started to transform the Canadian ELCC context (Akbari \& McCuaig, 2017).

In 2006, the Organization for Economic Co-Operation and Development (OECD) revealed that Canada's public expenditure on early childhood programs were the lowest of the twenty developed countries that were part of an international review (OECD, 2006). At the same time, an investment narrative that challenged the underfunded and forgotten Canadian ELCC sector started to emerge. This narrative was supported by economic-returns paradigms (Bennet \& Newman, 2004; Heckman \& Cunha, 2000; Mitchell, Wylie, \& Carr, 2008; OECD, 2011) and by new understandings about neuroscience and brain development, which sustained the brain's malleability, experienced a peak during the first five years of human development (McCain \& Mustard, 1999; McCain, Mustard, \& Shanker, 2007).

The investment narrative resonated strongly in PEI and as a result, unprecedented and rapid transformations reformed the early childhood sector from a focus on childcare to a system with a focus on early learning (Arias de Sanchez, Doiron, \& Gabriel, 2012). Some of the initial changes included moving early childhood programs from the departments of Social Services and Seniors to Education and Early

\footnotetext{
${ }^{1}$ University of Prince Edward Island, Faculty of Education, Charlottetwon, Canada, e-mail: gsanchez@upei.ca, ORCID: https://orcid.org/0000-0003-1408-413X

2 University of Prince Edward Island, Faculty of Education, Charlottetwon, Canada, e-mail: aroach@upei.ca, ORCID: https://orcid.org/0000-0001-9892-7370

${ }^{3}$ University of Prince Edward Island, Faculty of Education, Charlottetwon, Canada, e-mail: brobichaud@upei.ca ORCID: https://orcid.org/0000-0002-4837-6926
} 
Learning and transferring kindergarten to the school system (Human Resources and Skills Development Canada, 2012). This last move was fundamental for the overall early childhood structure, mainly because close to over half of certified early childhood educators (ECEs) who worked in kindergarten at that time were provided the option to move to the school system and to obtain a Bachelor of Education degree. Given that this transition resulted in experienced ECEs leaving the early childhood sector, provincial Government authorities recommended that an exhaustive review of early learning be conducted to devise "a plan for a sustainable, high quality, accessible early childhood system" (Mella, 2009, p. v). The Early Years Report (Flanagan, 2010) was a response to that call. The report gathered data from families and parents as well as from some leaders and educators to develop a vision for PEI children and a framework for early childhood.

The plan to re-design and re-vitalize the early childhood system across the province was then put forward and in May 2010, the Government announced the Prince Edward Island Preschool Excellence Initiative (PEIPEI). According to the Provincial Government, "The plan provides[ed] the Island's largest ever increase in investment in early learning for children from birth to age four" (Government of PEI, 2010, p. 2).

The PEIPEI was set forth changes across the sector, including a designation of and funding for Early Years Centres (EYCs). While EYCs remained privately delivered, either for-profit or non-profit, this major change resulted in new provincial policies that managed centres in a more public manner (Government of PEI, 2010; Human Resources and Skills Development Canada, 2012). The new policies included regulated fees for parents, required spaces for children from infancy to school entry age, children with special needs, a compulsory parent advisory committee, a wage scale and benefits for staff, a new provincial early learning curriculum, revisions to certification and training requirements for early childhood educators, and a formula-based funding approach for centres with an early years designation (Human Resources and Skills Development Canada, 2012).

Changes to the ELCC system have been extensively examined across Canada, particularly concerning their impact on young children and parents (Arias de Sanchez et al., 2012; Heydon, Moffatt, \& Iannacci, 2015; Leherer, 2012; Peterson, Morrison, \& Morrison, 2012; Vogler, Cravello, \& Woodhead, 2008) and on the system's professionalization (Baldacchino, Gabriel, Doiron, Roach O'Keefe, \& McKenna, 2015; Roach O'Keefe, Hooper, \& Jakubiec, 2019). However, little is known about how system-wide changes have impacted ECEs practices and their roles. This study explored this void.

The study is framed within Bronfenbrenner's theoretical work $(1979,2005)$, which proposed that development cannot be separated from social and cultural multi-level environments. Bronfenbrenner represents these multi-levels through concentric systems- chronosystem, macrosystem, mesosystem, and microsystem- that impact and are being impacted by an active individual at a particular historical time. This bidirectional dynamic implies that individuals experience shifts when changes happen at any layer of the multilevel environments. We also draw from (Tilleczek, 2011 2014) cultural nesting approach to interpret the shifts and transitions described by participants. Rooted in Bronfenbrenner's work, Tilleczek (2012) understands that "transitions often imply issues of identity fit and development" (p. 13) or what this author described as processes of being, becoming, and belonging (2011, 2014). By situating ECEs at the centre of ecological multilevel environments, the study explored how the PEIPEI impacted and is being impacted by these educators as they navigate the transitions within system-wide changes over time, which Bronfenbrenner asserted was important in understanding proximal processes and the complex reciprocal interactions between systems (Bronfenbrenner \& Morris, 1998; Roach O’Keefe, 2018).

The following questions guided the study: (1) What has changed in PEI early learning and child care during the last ten years? (2) What are the strengths of the PEI early learning and child care system? (3) What limitations still exist in the PEI early learning and child care system? and (4) What are the opportunities for the early learning and child care system to continue to develop?

By critically examining the experiences of ECEs who have worked within the PEIPEI for the last ten years, the study also provided a space for better understanding how their silent voices of knowing (Basler 
In-between spaces of policy and practice: Voices from ...

Wisneski \& Reifel, 2012; Canella, 2005) permeate early childhood education's history. With a focus on strengths and limitations, the study will contribute to unpacking and better problematizing how systemwide decisions influence the evolving Canadian and international early learning and child care agenda.

\section{Method}

This research employed a qualitative research design (Sandelowski, 2010). After receiving ethics approval, purposive sampling (Patton, 2015) was used to invite PEI early childhood educators to participate in individual interviews (Fontana \& Frey, 2000; Tierney, 2002). Recruitment took place through the PEI Early Childhood Development Association (ECDA) membership list. A letter of invitation was sent to 10 ECES who held the following participation criteria: (a) that the educator has been working in the PEI early learning and child care for at least ten years, and (b) that the educator worked in a provincially regulated Early Years Centre, and (c) that the educator held at least a two-year diploma that was certified under the Provincial Government's Regulatory Board. Additionally, recruitment compromised at least one participant from each of PEI counties, in order to garner a wide variety of perspectives from educators representing the Island rural and urban areas. Seven ECEs (six female and one male) from different EYCs agreed on participating; three of them held a Supervisor role.

Researchers considered a post-modern interviewing stance (Fontana \& Frey, 2000) in which the interview allows for co-construction of understanding, and the enrichment of the data, between participants and researcher (Tierney, 2002). Two of the researchers developed separated interview protocols that aligned with the study's purpose and the research questions. With the understanding that each other's feedback increases the opportunity to comprehend how well participants might understand the interview questions and whether their understanding is close to what the researcher intends or expects (Patton, 2015), the two researchers revised and refined the individual interview protocols and together, constructed the final one. Supported by Krueger and Casey interviewing model (2009), the final protocol included introductory questions (i.e., "Tell me about your professional background"); transitory questions (i.e., "Ten years ago when the PEIPEI was announced, what was your initial reaction?"); key questions (i.e., "In your opinion, what are the strength of the PEIPEI?"); and closing questions (i.e., "How would you like to see the early childhood field evolve in PEI?"). Participants signed a written consent form and also provided verbal consent prior to the interview. Each interview lasted approximately one to one and a half hours and were fully recorded and transcribed. Participants were provided with a copy of a transcript of the interview to check for accuracy and to provide credibility to the study.

Researchers also made detailed and descriptive notes concerning their observations, reactions, direct quotations, insights, inspirations, and questions (Patton, 2015) promptly after the interviews. Researchers worked independently to conduct a thematic analysis approach (Babbie, 2010). Recurring consistencies and inconsistencies (Patton, 2015) were then identified and organized in individual shared folders for each of the study questions. Researchers then compared their analysis to identify trends, similarities, and differences (Patton, 2015) across the interviews. The University of Prince Edward Island (UPEI) Ethics Board approved this study research protocol.

\section{Results}

The PEIPEI initiative was built to provide the youngest Islanders with "the strongest start possible" (Government of PEI, 2010, p.10). Undoubtedly, the PEIPEI also offered fundamental changes for children, families, early childhood centres' owners and operators, and early childhood educators. With a focus on strengths and limitations, the goal of this study was to unpack how the PEIPEI system-wide decisions have impacted ECEs practices and roles. In response to our research questions, our analysis resulted in the emergence of two main themes: (a) Unraveling transitions, and (b) searching for professional identity.

Unraveling transitions is discussed below and responds to research question (1) What has changed in PEI early learning and child care during the last ten years? (2) What are the strengths of the PEI early learning and child care system? Highlights include reflections on infant care services, the curriculum document, and curriculum implementation. 
Professional identity is subsequently discussed in response to research questions (3) What limitations still exist in the PEI early learning and child care system? and (4) What are the opportunities for the early learning and child care system to continue to develop? Reflections are discoursed on expectations and professionalism, loss: leadership and mentorship, wage grid, recruitment and retention; and opportunities for advanced learning and development.

\section{Unraveling Transitions}

Participants discussed the unravelling and negotiation amongst several transitions, including: horizon of change, infant care services, and negotiating the curriculum and its implementation. These transitions are described below.

\section{Horizon of Change}

"The PEIPEI was the right thing to do. Yes, it's been a long journey...the process is going on and on, and there is no finish line... but we are on the right path" (ECE 3, February 2021). The launching of the PEIPEI was accompanied by the feeling that something "good" was happening in Prince Edward Island. Consensus existed among participants that the assurance of receiving financial support was a fundamental turn-around point for most early childhood centers when deciding to become provincially regulated. Participants agreed that with the PEIPEI, values and beliefs about equity, sustainability, and accessibility were finally "put on paper" (ECE 1, January 2021). "Finally, ... It was kind of like a 'finally'... I was very excited" (ECE 2, January 2021). As a sector that has long experienced transitions, government effort to redesign and revitalize the early childhood system sparked a sense of empowerment and pride amongst ECEs.

While participants reflected on some of the challenges-that accompanied the implementation of the PEIPEI, they also pointed out that they soon adapted and that they "were up for the challenge" (ECE 7, March 2021). For example, when asked about the announcement of the PEIPEI initiative, ECEs agreed that the implementation happened rapidly and felt like "a whirlwind" (ECE 1, January 2021) that created panic and a certain level of discomfort. "PEIPEI came quickly, and it had to be implemented fast...The intent at that time was to make it smooth... but it was chaotic" (ECE 6, March 2021).

It was kind of like a two-fold. We were excited about some positive changes coming our way but we were terrified at the same time because we were losing a massive component of our programming and we were losing a lot of educators (ECE 5, February 2021).

Participants' quick adaptation to the changes was also indicated regarding pedagogy: "All of a sudden they were telling us we have to do emergent curriculum" (ECE 1, January 2021). While participants shared that training sessions, workshops, and centre visits by the then Department of Education and Early Childhood Development supported that shift, a sense of urgency permeated the process through those initial months. "I definitely remember there was a lot of training sessions... I remember doing a lot of the training around the ELF and going to various workshops." (ECE 2 January 2021).

\section{Infant Care Services}

Prior to the implementation of the PEIPEI, access to quality infant care services was reported as a primary challenge for parents and families (Government of PEI, 2010). The Early Years Report noted that at the time, "of the 2948 estimated full time spaces, only 192 full time equivalent spaces [were] available for children younger than two years of age" (MRSB Group, 2009, as cited in Flanagan, 2010, p. 76). Given this, a key feature of the PEIPEI brought about changes to infant care services to provide new and expanded options to parents for infant care and learning in licensed EYCs and Infant Homes (Government of PEI, 2010). Under PEI's Early Learning and Child Care Act Regulations (Government of PEI, 2018), "the maximum group size for infants receiving services at a licensed centre is six infants" (p. 16). These changes have increased the number of infant spaces across PEI from 192 reported in 2010 to 407 reported in 2020 (Akbari, McCuaig, \& Foster, 2020). According to participants, even though this inclusion raises particular challenges, the policy was and continues to be one of the strengths of the initiative, 
In-between spaces of policy and practice: Voices from ...

The infants, there's always been a little bit of a challenge because it dramatically changes how the centre runs in the sense that all of a sudden, if even it's only six children, they can only be with these ones for a certain amount of time. So, it changes how your staff, the shift times, who can go where, and when... But at the same time, it's also enriching (ECE 1, January 2021).

Taking in infants was a change because we hadn't had infants before. I mean, it wasn't really a big deal. There was a little bit of figuring out about how we would do that and where, for the space and all that. But it worked for us (ECE 3, February 2021).

\section{The Curriculum Document}

The creation of the early years' curriculum document was consistently highlighted as the most critical strength of the PEIPEI. Rooted in social pedagogy, the PEI Early Learning Framework (ELF) (Flanagan, 2011) became the first early childhood curriculum guidelines for the province. Rather than prescribing pedagogy, the ELF curriculum design offers a broad and holistic model, and its emergent approach allows and challenges educators' reflexivity. The PEI ELF three learning principles are built around relationships, the consideration of the environment, and children's experiences (Flanagan, 2011). Rooted with a social pedagogical approach, the ELF promotes the idea that young children's learning is influenced by quality interactions between children and adults and by the experiences that children have through play and exploration.

Participants pointed out that the ELF gave a common language to the field and created a certain level of consistency about pedagogy. ECEs indicated that since its implementation, the ELF had deepened their understanding of the whole child and provides a sense of credibility among parents and the overall community, "We have something with substance that we can show and use to show this is why we're doing what we're doing" (ECE 2, January 2021);

The curriculum has changed the public perception.... We are somebody that has a specialized base of knowledge. We're not babysitters, we don't just provide supervisory care, we are actual teachers who have a clue [about] what we're doing (ECE 2, January 2021).

Despite recognizing the importance of having a curriculum framework for the first time, participants also indicated that the lack of prescriptive statements in regards to goals, strategies and assessment still creates confusion. Overall, ECEs agreed that this confusion jeopardizes the provision of quality practices as educators are challenged to make pedagogical interpretations; this issue seems to become more complex when practitioners do not hold a two-year diploma.

\section{Curriculum Implementation}

Struggles with the implementation of an emergent curriculum were reported in regards to planning, documentation, and assessment. As the ELF indicates, ECEs working in Early Years Centres are required to plan and develop emergent programming that is relevant to the children and their interests, create learning stories and portfolios to document children's ongoing learning and growth, and develop and carry out assessment strategies such as continuous and thoughtful observation of children's interests and development (Flanagan, 2011). To effectively engage in this iterative process of emergent planning, ongoing documentation, and authentic assessment, ECEs must also meaningfully and thoughtfully reflect on their pedagogical practice both individually and as a team (Flanagan, 2011, p. 173)

While participants spoke positively about the shift to emergent curriculum and acknowledged the importance and necessity of the iterative planning process, even ten years later, they explained further that time and resources to engage in and complete this essential work is a persistent issue. One participant reported that while ECEs are meeting the requirements laid out in the ELF regarding planning, documentation, the creation, and maintenance of portfolios, and engaging in reflective practice, "it's always been a challenge to allow staff to be off the floor [to complete these expectations]" (ECE 3, January 2021). When asked about the logistics of scheduling planning time for ECEs, another participant expressed that "[ECEs] get an hour and a half a week... you pray that the kids will sleep for at least 30 or 45 minutes... because that's [their] paid planning time. When do [they] get [their] supplies? Just on the run?" (ECE 1, January 2021). 
The ELF also indicates that, ECEs are to "... reflect on their observations at a later time, and... analyze their observations based on their knowledge of the child, and their professional interpretation of what they see" (Flanagan, 2011, p. 155). Findings from this study reveal that the time required for ECEs to meaningfully and intentionally engage in reflective practice is an ongoing struggle. As one participant shared, "You need to reflect on your own pedagogy, on your own work... and that's again, more time. And we don't have that... there's not a lot of time for that sort of reflection" (ECE 2, January 2021).

In discussing a solution to the pressing issue of time, one ECE suggested that additional funding should be made available to hire and pay an additional staff person to relieve ECEs for their paid planning time each week. From this ECEs perspective, additional funding would ensure that ECEs are treated “... like professionals within the model so that they have time for planning, observation, [and] documentation, just like other educators do for other children" (ECE 3, January 2021). Aligned with previous research (Roach O'Keefe, Hooper, \& Jakubiec, 2019), these sentiments connect to the broader issue outlined previously concerning the disconnection that ECEs feel between the Early Childhood sector and the PublicSchool System in PEI,

I think that there's a disconnection with all the work that we're doing here. When the children go to school, I feel like there's a disconnect between what we're doing here and what is going on in the school system... I've always felt that that was kind of a disconnect and disservice to the children that we've had here (ECE 2, January 2021).

\section{Searching for Professional Identity}

Participants discussed how they continue to search for professional identify amidst the transitions, and they discussed: an increase in their work expectations, a loss of leadership and mentorship, the wage grid, recruitment and retention, and the appetite for advanced learning and development. These points will be described in subsequent sections of the paper.

\section{Expectations and Professionalism}

Since the PEIPEI implementation, expectations for the early learning and child care field rapidly grew. Despite that accountability was perceived as necessary, ECEs concurred in that paperwork and pedagogical demands escalated, "They want more, and more, and more from us, but the financial resources were not put there (ECE 7, March 2021). Interestingly, ECEs also reported that parents' expectations have also increased, "Parent expectations have gone up a lot... because we told them "Hey, we're professionals! We're available to you..." (ECE 1, January 2021); “... the expectations keep growing because we keep, rightly so, building ourselves up as being absolutely fabulous" (ECE 5, February 2021).

After ten years of the PEIPEI implementation, most participants explained that the initiative is still in transition. Participants agreed that despite of consistently having to experience sudden changes they are always ready for new challenges, "You get things thrown at you all the time. So, I always say, and it's terrible, "adapt or die". As a profession, you either adapt or you leave, right?" (ECE 5, February 2021);

You have to be able to take things on a moment's notice. And I feel like that's really stayed in the sector. They made an announcement today; we have to implement it by two weeks from now... We're all pretty quick on our feet (ECE 2, February6 2021).

\section{Loss: Leadership and Mentorship}

The PEIPEI initiative was parallel to two significant changes in the early childhood workforce: a massive movement of certified and experienced ECEs to the school system, and a new wage-grid for ECEs who stayed within early learning and child care services.

Participants shared the same upsetting discomfort when talking about losing the most experienced educators, who were often described as mentors and leaders, “... all of a sudden all of these new changes were coming in and that people that we looked up to were gone" (ECE 7, March 2021); "I feel like some of our pedagogy was lost because some of our long-standing members left and then it was a lot of newbies" (ECE 6, March 2021). This finding is consistent with previous research exploring the professionalization of the field (Roach O'Keefe et al., 2019). 


\section{Wage Grid, Recruitment, and Retention}

The PEIPEI described ECEs as professionals and indicated that the implemented measures were going to maintain a stable workforce (Government of PEI, 2010). One of the most important changes was the creation of a new wage grid for those ECEs who stayed in early childhood. This particular change encompassed a sense of excitement but also nervousness, "The idea was great because it didn't matter where you work across the Island but you knew that we were having the same working situation" (ECE 3, January 2021).

In 2010, the wage grid proposed a five-year strategy that combined ECEs education and job position. The 2010 wage grid included: (a) Entry level (which included three courses); (b) Level 1 (which included a one-year certificate); and (c) Level two (which included a two-year diploma) (Government of PEI, 2010. Between 2010 and 2017 the language of the wage grid changed to ECE level 1 (entry level), ECE level 2 (one-year certificate), and ECE level 3- (two-year diploma). By 2019, two new levels were included at the bottom of the grid: a 3 three 30 hours course level, and an uncertified staff level (Government of Prince Edward Island, 2019).

Since 2010, Directors have always been paid the highest at the top of the grid. The impossibility to move beyond that step was certainly manifested as a serious concern, and limitations on ECE's career development and progression, which has the potential to impact recruitment and retention of staff.

Overall, participants agreed that the grid and its amendments appear to better fit the new staff, "Is good to have a grid....but for people with more training and experience it is a slap on the face... we are capped" (ECE 5, February 2021);

I think it's good that ECEs were given raises. I think it's good that there are levels. The frustration is for those of us who have been in the field for a very long time, it meant we were capped right away... the wage grid did not reflect anyone that has been in [the field] for a long time (ECE 4, February 2021).

In fact, ECEs retention and recruitment have fallen since 2010 and continue to be a serious struggle for the overall system (Flanagan, 2019; Flanagan \& Beach, 2016). "They thought we were having new people, we were going to attract more people...well, it did not happen, on the contrary..." (ECE 7, March 2021). Participants pointed out that despite being part of the Department of Education and Life Long Learning, the early childhood working situation is fragile and unequal, "Yes, we are now under the government umbrella, but we're not in the same position like the schools are"(ECE 5 February 2021);

\footnotetext{
There's a fair bit of inequity in terms of how ECE is treated within the whole PEI education system when you compare their training and level of responsibility. All of the ECEs here have the two-year College diploma, yet they're paid less than educational assistants in the school system, who have the same level of training. Even though we're all part of the Department of Education [and Life Long Learning], there's a lot of inequity there. And the staff is aware of that... They say the department says that they recognize the importance of early childhood education and yet there's a pay inequity there. Mixed messages. (ECE 3, January 2021).
}

Participants also indicated that issues with recruitment and retention affect the consistency and the quality of their services,

I think when there's always that turnover you're always training someone new. So, it makes really hard to get into a good rhythm. And then all of a sudden somebody's gone and then you have to train somebody new. I feel like that's something. And then the children always have to get used to somebody new. And you're starting over with building those relationships (ECE 4, February 2021).

The interviews revealed that ECEs feel empowered about their work, particularly when discussing their pedagogical role, "what we do might change a child's life" (ECE 2, January 2021). Yet, there was also a need to consistently having to justify and advocate about the importance and the professionalism of their work, "You can't be a so-called professional if you don't have the work environment that supports that professional practice" (ECE 3, January 2021).

\section{Advanced Learning and Development}

In 2010, the PEIPEI introduced revisions to ECEs and Directors' certification and training requirements: "With Government's assistance, new training programs are being developed to allow all 
program staff to become certified over the next several years and to create an integrated career ladder for staff from the entry level through to post-diploma and degree training. This initiative will put Prince Edward Island at the forefront of Canadian provinces" (Government of PEI, 2010, p. 3).

However, revisions to Director's training were not followed up and as participants indicated, "... they're not requiring the person who is in charge of the whole centre to have any more education than the people they're supposed to be mentoring" (ECE 1, January 2021); "You can meet the requirements and have 30 years of experience but still get paid the same as another director on their first day on the job" (ECE 7, March 2021).

Participants noted the need to develop their professional training further. Even though they enormously appreciated the possibility to participate in the local early childhood conferences twice a year, participants also concurred on the need to have different options for ongoing training, particularly for experienced ECEs,

Workshops are great for our novice teachers, the people who are still learning, who are still struggling, who need those ideas. But when we get up to the teachers who are at the expert [level]... we need something deeper than two and a half hour workshops. We need time to dig deep (ECE 3, February 2021).

Having more levels of non-certified staff was also pointed out as a struggle for quality and service provisions, "I would love to see a minimum of a diploma but headed towards a degree. No more of these three courses or one year or whatever.... It's got to go to a minimum of two years" (ECE 1, January 2021).

Overwhelmingly was the claim for a career path, "The thing about ECE... beyond being a director, it doesn't feel like there's any place to go. It feels like, okay, I'm an ECE, but what next?" (ECE 6, March 2021); “There's not really room to move up. I think that's frustrating for a lot of people" (ECE 4, February 2021).

Sometimes I feel that there's not a big career ladder in this field. You're kind of an active floor staff or you're a director, or you move up maybe to a higher position such as working with the department as a coach. But... there's no inbetween (ECE 4, February 2021).

\section{Discussion}

For decades authoritarian perceptions that viewed ECEs as unskilled practitioners (Basler Wisneski \& Reifel 2012; Osgood, 2011; Urban, 2010) rested unexamined within the social and multi-level environments (Bronfenbrenner, 1979, 2005) that framed early learning and child care services. The investment narrative that emerged in the early 2000s provoked a disruption of these historically constructed perceptions and brought hope and optimism to a sector that started to be described as professional (Brock, 2012; Dalli, 2008; Lazzari, 2012; Urban, 2008). With these changes in the discourse, early learning and child care emerged as a panacea for solving social problems (MacTavish, 2012; Moss, 2008) while ECEs were pushed to forge a new identity (Arias de Sanchez et al., 2012; Roach O'Keefe \& Moffatt, 2013; Shaw, 2015).

Although system-wide changes happened quickly in PEI, ECEs indicated that after ten years these changes continue to be in transition. Although transitions are recognized as processes rather than events (Peters, 2010), statements such as "there is no finish line" revealed feelings of incompleteness and frustration. Tilleczek (2012) described these motions as "nested transitions" (p. 12) and explained that they create constant tensions in individuals' processes of being, becoming, and belonging. Our findings indicated the existence of unrevealing tensions faced by ECEs as they try to negotiate their status within the contradictory discourses of becoming professionals while still working in a system that offers precarious employment conditions. What was particularly concerning were the ways in which our experienced participants manifested the feeling of walking in-between policies and opportunities, which in turn conflicted with their professional processes of being, becoming, and belonging (Tilleczek, 2011, 2014).

This in-between experience emerged within the policy expectations to become professionals while at the same time having (being) to advocate for what their profession entails. In our study, ECEs showed 
In-between spaces of policy and practice: Voices from ...

the consistent need to have to validate and justify who they are and who they can be (being and becoming); this theme emerged as an exhausting endeavour that reveals a fragile sense of belonging within a system that keeps changing and asking them for more. Statements like "We are not babysitters" and "What we do matters and affects children's lives day-by-day across the country" are evidence of this conflict. Paradoxically, our data also indicated that educators felt empowered by their ability to figure out how to accommodate change and by consistently demonstrating that they were resilient and "up for the challenge" (ECE 2, February 2021). We questioned if this sense of resilience has become a taken-for-granted discourse that plays against the profession by sending the message of being "absolutely fabulous" and by promoting the idea that "whatever happens, we will make it work."

Similarly, the in-between paradox emerged also when participants discussed the curriculum guidelines. Although the PEI curriculum framework provided a common pedagogical language that empowered educators and aimed at fostering their critical thinking, reflective practice, and professional autonomy, participants pointed out that the alternatives for these professional demands are limited and create the never ended feeling of "be a so-called professional, but without having the work environment that supports that professional practice" (ECE 1, January 2021). While participants made clear that the PEI Early Learning Framework is one of the key strengths of the changes over the past ten years, their reflections indicated that there remains a disconnect between the pedagogical demands of working with an early learning framework and with the supports made available to ensure professional reflexivity. Undoubtedly, this ongoing tension continues to blurry the pathways for developing (becoming) a highly qualified professional workforce.

Data also demonstrated that educators felt a sense of being in-between when discussing their working conditions. The experienced ECEs who participated in this study understood that changes in the provision of "honourable" (ECE 4, February 2021) wages and benefits are a must for the system's improvement. However, they also understood that an increase in wage policies alone would not solve the overall "early childhood problem" (ECE 5, February 2021). Working conditions, including ECE wages, have been recognized as important indicators of quality in early childhood education programs (Atkinson Centre, 2017). Highlighted as a positive change within PEI's early childhood sector, the introduction of and amendments to the wage grid (i.e., in 2016 and 2019) provided ECEs with a pay increase based on education and years of experience. However, challenges remain as pay is still low (Flanagan, 2019) and as wage increases stop after five years. For directors, this is compounded as there is only one pay step. As a result, recruitment and retention of trained ECEs persists as ongoing issue which in turn problematizes quality and program consistency as early years centres are continually hiring and training new educators.

The limited possibilities for educators' career pathways present a serious issue of professional equity when comparing educators that have chosen to work in early learning and child care to those that work in the formal education system. Once more, our data presented how ECEs move in- between paradigms as it is debatable to be called a professional if the career pathway stops in a grid that only focuses on five years of work experience with no options for additional education or future career development. It also exemplifies the lack of recognition of lifelong learners - those who want to continue learning and contributing to the creation of new knowledge, which goes beyond in-service skills training (National Association for the Education of Young Children, 2011).

As this study has illuminated, the positive aspects of the PEIPEI have been met with persistent challenges. Notably, and despite ECEs consistent efforts for having to validate their professional being, becoming, and belonging (Tilleczek, 2011, 2014), the experienced educators that participated in our research showed little compliance and offered professional suggestions to the many issues they faced daily in their practices. The participants of this study have demonstrated that their individual and collective experience and knowledge offers important insight on a path forward. These educators have also provided a glimpse of the bidirectional dynamic of Bronfenbrenner's (2005) multi-level environments: they were at the centre of many of these changes, and while they experienced these on a microsystem level, they were also using their voice to influence their exosystem (what had influenced them on a societal/ policy level) and through the chronosystem. They were both influenced by the changes and they were exerting their 
power to potentially influence their future in the system.

At the outset of the PEIPEI implementation, the transition of experienced kindergarten teachers to the public-school system resulted in a sense of loss for the field; however, those that continued and those have since joined the sector have themselves grown and flourished as mentors, pedagogical leaders, and advocates for the system. Not surprisingly, their recommendations focused on the improvement of the work conditions, particularly regarding wages and benefits. But they also offered suggestions pertinent to their daily needs, such as adding a full-time staff that allows educators to take time off the floor to complete the heavy demands of planning and documentation. Participants also offered important insights in regards to professional qualifications and training for directors and educators,

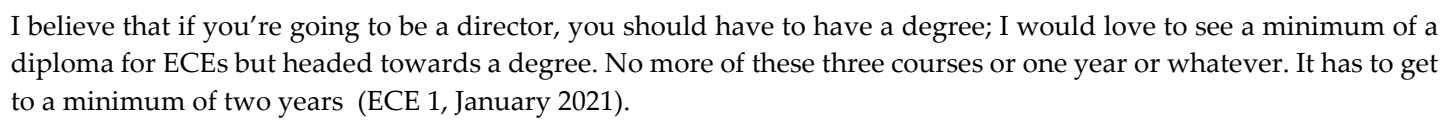

\section{Conclusion: Navigation of the Space in Between}

The findings from this study have shed light on the strengths and limitations of the Preschool Excellence Initiative as reported by early childhood educators working in Early Years Centres across PEI. Participants of this study expressed that the sector and those that operate within it (e.g., ECEs, ECE supervisors and directors) are still experiencing this transition. As a result, ECEs described that the changes brought about by the introduction and implementation of the PEIPEI have resulted in an ongoing tension between the strengths and limitations of the initiative; tension that has and continues to impact the early learnings and childcare system across the province. The participants' reflections revealed further that as these changes unfolded and expectations rose over the past decade, those working within the early learning and childcare system have been striving to navigate and merge the space in-between the strengths and gaps of the Preschool Excellence Initiative. At present, ECEs describe feeling that they remain in this liminal space where complex and contradictory systems and discourses continue to build barriers and interrupt the fluidity of a system-wide change.

While the PEIPEI impacted and changed the day-to-day reality and practice of early learning and childcare across the province, ECEs have equally impacted this system-wide change, effecting a bidirectional dynamic between policy and practice (Bronfrenbenner, 2005). For instance, the PEIPEI brought about rapid changes to areas such as funding, accessibility, and curriculum. Moreover, and perhaps most importantly, passionate, knowledgeable, and experienced ECEs across PEI also impacted these shifts as they carried out the new PEIPEI system, embraced a new pedagogical approach, and became advocates for themselves and the sector at large. Yet, as the participants of this study have demonstrated, the limitations of the PEIPEI have kept ECEs in this in-between space as their individual and collective capacity to impact the policies that guide their practice has been hindered and their voices unsought.

This study presents some limitations. A small sample was chosen for this study, however this is the norm in qualitative studies. The investigation represents the responses from a small sample of educators who live in PEI. In addition, a second limitation of this study is the lack of culturally diverse representation by participants; while PEI has become very diverse in the last decade, sample of participants does not represent the diverse nature of educators living on the Island. Readers from elsewhere must read this research with their own context in mind, to determine if results might be applicable in their environment.

The findings from this study may contribute to the discourse and approach to system-wide decisions and may further influence the evolving early learning and child care agenda both in Canada and around the globe. As the experienced ECEs who participated in this study have suggested, the changes first set in motion by the PEIPEI must continue to progress and promote equity and growth within the early learning and childcare system. With the recent announcement by the Government of Canada (2021) regarding plans to create and implement a national childcare system over the next five years in mind, we hope that the findings from this study have demonstrated that the voices and perspectives of ECEs must be meaningfully sought, heard, and considered going forward as they offer significant insight, knowledge, and suggestions 
for an equitable path forward.

\section{Declarations}

Acknowledgements: Not Applicable.

Authors' contributions: Arias de Sanchez \& Roach O'Keefe, conceived, designed and conduct the investigation; Robichaud transcribed the interviews; Arias de Sanchez \& Robichaud analyzed the data and wrote the paper; Roach O'Keeffe provided feedback and editing.

Competing interests: The authors declare that they have no competing interests.

Funding: The study was funded by the University of Prince Edward Island (UPEI) Internal Research Grant and the Social Sciences and Humanities Research Council (SSHRC) Explore Research Grant.

\section{References}

Akbari, E., \& McCuaig, K. (2017). Early childhood education report: 2017. Retrieved from https://ecereport.ca/media/uploads/2017-reportpdfs/ece-report2017-en-feb6.pdf

Akbari, E., McCuaig, K., \& Foster, D. (2020). Early childhood education report: 2020. Retrieved from https://ecereport.ca/media/uploads/2021-overview/overview2020 final2.pdf

Arias de Sanchez, G., Doiron, R., \& Gabriel, M. (2012). An examination of international early childhood curriculum documents. Canadian Children, (37)2, 29-47. https://doi.org/10.18357/jcs.v37i2.15199

Atkinson Centre. (2017). Prince Edward Island profile 2017: Trends in ECEC from 2011-2017. Retrieved from https://ecereport.ca/media/uploads/2017-profiles-updated/pei_final-feb14.pdf

Babbie, E. (2010). The practice of social research. Belmont, CA: Wadsworth, Cengage Publishing.

Baldacchino, A., Gabriel, M., Doiron, R., Roach O’Keefe, A., \& McKenna, J. (2015). From child-minders to professionals: Insights from an action research project in Prince Edward Island. Canadian Children, 40(1), 11-129. https://doi.org/10.18357/jcs.v40i1.15214

Basler Wisneski, D., \& Reifel, S. (2012). The place of play in early childhood curriculum. In N. File, J. Mueller, \& D. Baslerwisneski (Eds.), Curriculum in early childhood education: Re-examined, rediscovered, renewed (pp. 176-187). New York, NY: Routledge.

Bennet, J., \& Newman, M. (2004). Early childhood major challenges: Review of early childhood education and care policies in OECD countries. Prospects, 34(4), 423-433. https://doi.org/10.1007/s11125-005-2714-5

Brock, A. (2012). Building a model of early years professionalism from practitioners' perspectives. Journal of Early Childhood Research, 11(1), 27-44. https://doi.org/10.1177/1476718X12456003

Bronfenbrenner, U. (1979). The ecology of human development: Experiments by nature and design. Cambridge, MA: Harvard University Press.

Bronfenbrenner, U. (2005). Making human beings human: Bioecological perspectives on human development. Thousand Oaks, CA: Sage Publications.

Bronfenbrenner, U., \& Morris, P. A. (1998). The ecology of developmental process. In W. Damon \& R. M. Lerner (Eds.), Handbook of child psychology: Theoretical models of human development (Vol. 1,5th ed.) (pp. 993-1028). New York, NY: John Wiley.

Canella, G. S. (2005). Reconceptualizing the field of early childhood education: If Western child development is a problem, then what do we do?. In N. Yelland (Ed.), Critical issues of early childhood education (pp. 17-39). New York, NY: Open University Press.

Dalli, C. (2008). Pedagogy, knowledge and collaboration: Towards a ground-up perspective on professionalism. European Early Childhood Research Journal, 16(2), 171-185. https://doi.org/10.1080/13502930802141600

Flanagan, K. (2010). The early years report: Early learning in PEI: An investment in the Island's future. Retrieved from https://gov.pe.ca/photos/original/edu_earlyyrsRpt.pdf

Flanagan, K. (2011). PEI early learning framework: Relationships, environments, experiences: The curriculum framework of the Preschool Excellence Initiative. Retrieved from https://princeedwardisland.ca/sites/default/files/publications/eecd_eyfrwrk_full.pdf

Flanagan, K. (2019). PEI workforce strategy project: Final report. Retrieved from https://princeedwardisland.ca/sites/default/files/publications/early years workforce strategy.pdf

Flanagan, K., \& Beach, J. (2016). Manitoba and Early Learning and Child Care Commission: Final Report. Governemnt of Manitoba. Retrieved from https://www.gov.mb.ca/fs/childcare/childcare news/pubs/final report.pdf

Fontana, A., \& Frey, J. (2000). The interview: From structure questions to negotiated text. In N. K. Denzin, \& Y. S. Lincoln (Eds.), Handbook of qualitative research (2nd ed.) (pp. 645-672). Los Angeles, CA: Sage Publications.

Government of Prince Edward Island. (2010). Securing the future for our children: Preschool excellence initiative. Department of Education and Early Childhood Development. Retrieved from https://gov.pe.ca/photos/original/edu_ExcellIniti.pdf 
Government of Canada. (2021). Budget 2021: A recovery plan for jobs, growth, and resilience. Retrieved from https://canada.ca/en/departement-finance/news/2021/04/budget-2021-a-recover-plan-for-jobs-growth-and-resilience.html

Government of Prince Edward Island. (2018). Early learning and child care act. Retrieved from https://princeedwardisland.ca/sites/default/files/legislation/e-.01-early learning and child care act.pdf

Government of Prince Edward Island. (2019). Early years centres hourly wage grid. Retrieved from https://www.princeedwardisland.ca/sites/default/files/publications/eyc wage grid.pdf

Heckman, J., \& Cunha, F. (2000). Policies to foster human capital. Joint Centre for Poverty Research (Working Paper N 154). Northwestern University: University of Chicago.

Heydon, R., Moffat, L., \& Iannacci, L. (2015). Everyday he has a dream to tell: Classroom literacy curriculum in a full-day kindergarten. Journal of Curriculum Studies, 47(2), 171-202. https://doi.org/10.1080/00220272.2014.1000381

Human Resources and Skills Development Canada. (2012). Public investments in Early Childhood Education and Care in Canada: 2010. Retrieved from https://ecd-elcc.ca/eng/ecd/ececc/early_childhood_education-eng.pdf

Krueger, R. and Casey, M. (2009). Focus groups: A practical guide for applied research. Thousand Oaks, CA: Sage Publications.

Lazzari, A. (2012). Reconceptualising professionalism in early childhood education: Insights from a study carried out in Bologna. Early Years, 32(3), 252-265. https://doi.org/10.1080/09575146.2011.651711

Leherer, J. (2012). A critical investigation of research, policy and programs that aim to support marginalized children's transition to kindergarten in Quebec. Canadian Children, 37(2), 19-29. https://doi.org/10.18357/jcs.v37i2.15198

MacTavish, M. (2012). Troubling government discourse on early learning websites: A critical analysis. Canadian Children, 37(2), 5-12. https://doi.org/10.18357/jcs.v37i2.15196

McCain, M., \& Mustard, F. (1999). Early years study. Final report. Revising real brain drain. Toronto, ON: Ontario Children's Secretariat.

McCain, M., Mustard, F., \& Shanker, S. (2007). Early years study 2. Toronto ON: Council for Early Childhood Development.

Mella, P. (2009). Every child a better future: Report of the public kindergarten commissioner. Charlottetown, PE: Government of Prince Edward Island.

Mitchell, C., Wylie, C., \& Carr. M. (2008). Outcomes of ECE: Literature review. Report to the Ministry of Education. New Zealand: Research Division.

Moss, P. (2008). The democratic and reflective professional: Rethinking and reforming the early years workforce. In L. Miller \& C. Cable (Eds.), Professionalism in the early years (pp. 121-130). Hodder: Arnold.

National Association for the Education of Young Children. (2011). Early childhood education professional development: Training and technical assistance glossary. Retrieved from https://www.naeyc.org/sites/default/files/globally-shared/downloads/PDFs/ourwork/public-policy-advocacy/glossarytraining ta.pdf

Organization for Economic Co-operation and Development. (2006). Starting strong II: Early childhood education and care. Paris: OECD Publishing.

Organization for Economic Co-operation and Development. (2011). Starting strong III: Early childhood education and care. Paris: OECD Publishing.

Osgood, J. (2011). Narratives from the nursery. London: Routledge. https://doi.org/10.4324/9780203143063

Patton, M. Q. (2015). Qualitative research and evaluation methods: Integrating theory and practice (4th ed.). Thousand Oaks, CA: Sage Publications.

Peters, S. (2010). Literature review: Transitions from early childhood education to school. Report to the Ministry of Education. Hamilton, New Zealand: University of Waikato.

Peterson, P., Morrison, W., \& Morrison, R. (2012). Early childhood services: Using narratives to explore parent's experiences of transition. Canadian Children, 37(2), 48-55. https://doi.org/10.18357/jcs.v37i2.15200

Roach O'Keefe, A. L. (2018). Remixing digital play in the early years: Learning stories from nested ecologies of one family. Charlottetown, PE: University of Prince Edward Island. Retrieved from https://islandscholar.ca/islandora/object/ir:22512/datastream/PDF/download/citation.pdf

Roach O'Keefe, A., \& Moffatt, L. (2013). Where to start? Early childhood educators, digital literacies, and professional learning final report. Charlottetown, PE: University of PEI.

Roach O'Keefe, A., Hooper, S., \& Jakubiec, B. (2019). Exploring early childhood educators' notions about professionalism in Prince Edward Island. Journal of Childhood Studies, 44(1), 20-36. https://doi.org/10.18357/jcs.v44i1.18775

Sandelowski, M. (2010). What's in a name? Qualitative description revisited. Research in Nursing \& Health, 33(1), 77-84. https://doi.org/10.1002/nur.20362 
In-between spaces of policy and practice: Voices from ...

Shaw, L. (2015). Maintaining a vision during times of change. In C. Ritchie (Ed.), Challenges and changes for the early years workforce: Working with children birth to 8 (pp. 49-70). New York, NY: Routledge.

Tierney, W. (2002). Undaunted courage: Life history and the postmodern challenge. In N. K. Denzin \& Y. S. Lincoln (Eds.), Handbook of qualitative research (2nd ed., pp. 537-554). Los Angeles, CA: Sage Publications.

Tilleczek, K. (2011). Approaching youth studies: Being, becoming and belonging. Toronto, ON: Oxford University Press.

Tilleczek, K. (2012). Early childhood transitions as critical praxis. Canadian Children, 37(2), 13-18. https://doi.org/10.18357/jcs.v37i2.15197

Tilleczek, K. (2014). Theorizing youth: Biography, society and time. In A. Ibrahim \& S. R. Steinberg (Eds.), Critical youth studies reader (pp. 15-25). New York, NY: Peter Lang Press.

Urban, M. (2008). Dealing with uncertainty: Challenges and possibilities for the early childhood profession. European Early Childhood Education Research Journal, 16(2), 135-152. https://doi.org/10.1080/13502930802141584

Urban, M. (2010). Rethinking professionalism in early childhood: Untested feasibilities and critical ecologies. Contemporary Issues in Early Childhood, 11(1), 1-7. https://doi.org/10.2304/ciec.2010.11.1.1

Vogler, P., Cravello, G., \& Woodhead, M. (2008). Early childhood transition research: Review of concepts, theory and practice. Working papers in early childhood development. The Netherlands: Bernard van Leer Foundation. 